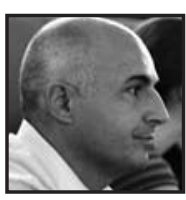

\title{
Commentary Navigating the Delicate Emerging Synchronicity Between Inclusion and Access
}

\author{
Frederic Fovet, McGill University
}

\begin{abstract}
The author examines how the synchronicity between access and inclusion is emerging in both the K-12 and post-secondary fields. Previously, both agendas have too often been artificially distinguished, it is argued. The article examines the opportunities this creates for the hands-on implementation of inclusive practices in the class, and considers some of the repercussions this organic merge will have at policy level. The author also highlights how the progressive overlap between inclusion and access best practices - such as Universal Design for Learning-benefits the full spectrum of diverse learners.
\end{abstract}

ducators often complain of the sheer abundance of theoretical and practice models with which they have been bombarded over the decades; interactive teaching, differentiated teaching, collaborative learning, and heutagogy being but a few examples of the myriad trends currently competing for the teacher's attention and dedication (Schaufeli \& Salanova, 2007). There is a phenomenon of theoretical "exhaustion" and it is therefore only natural for educators to fail, or to be reluctant, to see natural associations and overlaps between approaches that share perhaps far more than their name indicates. A striking exception, in this current decade, is the way the inclusion and access agendas are finally coming together and blending into one common concern for both $\mathrm{K}-12$ and post-secondary educators. 
Until still recently both these discourses were perceived, and promoted, as very distinct. Indeed, inclusion has now been on the books for over a decade but is still conceived by many as "best practice," and not necessarily as a principle that systematically delineates and structures everyday lesson planning, classroom intervention, or evaluation. In this sense, it is perceived as a central premise but one that is nonetheless often relinquished to second place after curriculum objectives, standardized testing imperatives, classroom management, and so forth (Tedesco, 2013). Equally, the access to learning discourse-and the legal and jurisprudential baggage it carries-is conceptually widely accepted in education. In practical terms, however, until recently the assumption was that this "access to learning" would happen after the fact, almost independently of curriculum development or classroom pedagogy, through the retrofitting efforts of "specialists." This is particularly true of the post-secondary sector, where everyone accepts the legitimacy of the Human Rights grounding for access to learning, but few, until recently, really accepted it might have any impact on mainstream pedagogy or assessment (Gradel \& Edson, 2010).

In practical terms, individual teachers, school administrations, school boards, and even jurisdictional policies do emphasize the need to achieve an inclusive classroom atmosphere, but it is striking, even over a decade into the unfolding of such policies, how tenuously these efforts are perceived as having any tangible links with the Human Rights dimension and the fundamental imperative to provide each student with access to learning (Beach, 2010). Experience and existing literature both evidence how the inclusive piece, while central to professional development, very much remains a standalone notion and objective. It is, in many ways, the "happy place" educators allude to and wish to achieve, but one that few have the means to attain (Kluth, Villa, \& Thousand, 2002). One of the sad realizations of the last decade is certainly the extent to which the inclusion discourse has remained prominent, but simultaneously hermetical. The focus on the notion as a goal has surprisingly little natural osmosis impact on classroom concerns and practices (Tedesco, 2013). One cannot, in fact, create inclusion without redesigning the curriculum and evaluation methods; this is the only way that an inclusive environment can emerge organically (Kosanovich, 2012; Katz, 2013). Similarly, it is high time for educators to realize that inclusion is the product of systematic everyday pedagogical processes, not an afterthought left to Friday afternoons, the day when all other class objectives are met, or pedagogical days. It is not a luxury but a basic.

Similarly, inclusion is not someone else's business; it is each teacher's responsibility (Villa \& Thousand, 2005). For too long now, educational systems have been morphed into vehicles of "referrals," in a process that disempowers educators and segregates students (Bradley, Danielson, \& Hallahan, 2002). There is a need to create ownership 
over inclusion, amongst our educators, and to put an end to the notion that if it is to be achieved, it requires the assistance of specialists, or that it is the sole panacea of individuals outside the classroom. This has allowed this otherwise fairly straightforward notion to become mystified to the point of creating a feeling of disconnect amongst an entire generation of classroom professionals. Of course, if we are to dig deeper behind this "culture of referral," it becomes quite plain that it is founded largely on the belief that inclusion requires expert, clinical knowledge of a wide array of impairments and diagnoses that have social or cognitive impacts on our learners. Educators have so internalized the medical model that it has become daunting for classroom practitioners to attempt inclusive approaches for fear that they are lacking essential skills. "Inclusion is not a place; it's a state of mind" has been a popular motto conveyed recently by popular digital media that carries much wisdom. Adopting that state of mind, and creating an inclusive classroom climate, does not require expert knowledge; it requires a practical, layperson's reflection on curriculum and delivery. It requires a systematic but not terribly complex individual analysis of the barriers that may be present in our classroom and a simple-but systematic_-desire to eliminate them.

At the other end of the spectrum, the access discourse has also far too long been anchored in a remedial model. The focus has been on assistive technology, clinical diagnosis, expert knowledge, parallel service provision, welfare model funding, diagnostic categorization, gatekeeping, and a perpetuated culture of "help" (Houghton \& Fovet, 2012). The disability movement itself has internalized the medical model and, while it advocates explicitly for a social model construction of disability, the very actors of this scene perpetuate practices, policies, and discourses that squarely place responsibility for access on specialists within a parallel system, not on the main actors of the classroom. This is equally true of the $\mathrm{K}-12$ sector and of the post-secondary environment, even if it manifests itself in differing ways.

In secondary education, this internalization of the medical model has led to the coding of needs, the creation of a two-tier system with "experts" on access imposing assistive practices while not themselves having responsibility for their pedagogical integration, and to the maintaining of segregated provisions inside education systems that proclaim themselves all-inclusive. It is a global phenomenon that sadly marks the failure of much of the mainstreaming efforts of the last decade: in the UK, for example, Pupil Referral Units (PRUs) too often become the daily setting of instructions for many (Munn \& Lloyd, 2005); most North American school boards meanwhile happily transfer funds, students, and responsibility to specialized non-profits instead of re-investing these funds towards the creation of effective inclusive settings inside state schools; finally, there are very few jurisdictions where the utter fear surrounding 
the management of autism spectrum disorder has not led to the creation of services so specialized that they render the very premise of inclusion as paradoxical. Education systems have been so intent on identifying individual needs that they have created conditions within which it is literally impossible, at present, to achieve or maintain a climate of inclusion (Visser, Daniels, \& Macnab, 2005).

In the post-secondary sector, inclusion has in fact hardly been tackled at all and while the legal imperative of access to learning has been paramount, the provisions to achieve this goal have ironically been entirely segregated. The presumption has been that the teaching body was not sufficiently aware, pedagogically skilled, dedicated, or willing to endeavour to tackle access to learning from the classroom angle. Until the relatively recent emergence of models such as Universal Design for Learning (UDL), there had literally been no attempts to address disability and access to learning from a perspective other than remedial (Gradel \& Edson, 2010). Segregated retrofitting, taking place outside the class itself, has been the only lens in use. The internalization of the medical model and of its presumptions has been so widespread that even the disability service providers are often the first to show reticence and suspicion towards a social model approach (Barnes, 2012). There are no inclusive practices or policies in place, despite the fact that the post-secondary sector has by now globally acknowledged the extreme diversity of its student population.

Where does that leave us, in this relatively new millennium? The simple, but perhaps most revolutionary, realization having occurred recently in the field of education is the extent to which a synchronicity does in fact exist between the concepts of inclusion and access to learning, and that one cannot be achieved without the other. For the $\mathrm{K}-12$ educator, this amounts to the progressive realization that access is not some ethereal notion that is much discussed in professional development but remains unachievable in the midst of everyday classroom challenges. It is the growing understanding that inclusion is not achieved or magically created by specialists with a developed understanding of impairments and diagnoses. It, in fact, emerges from daily practices that are primarily grounded in plain reflective work on our own curriculum development, classroom practices, and evaluation method. A model such as UDL, for example, has made giant strides in helping educators understand that they themselves have ownership of access to learning and that analyzing the classroom, through a social model or ecological lens, requires little more than common sense (Gordon, Gravel, \& Schifter, 2009). UDL does not focus on remedial action targeted at a specific need or impairment, but seeks instead to widen access through simple processes requiring little specialist or clinical knowledge. By encouraging teachers to offer multiple means of representation, expression, and engagement, the model reduces dramatically the 
reliance on highly specialized interventions and seeks rather to widen access in the class to the greatest number possible through the teacher's reflection on possible generic barriers (Rose \& Gravel, 2010).

This reflection leads to an identification and analysis of possible barriers but requires no in-depth understanding of the multiple impairments present in our classrooms; what it does require is the desire and ability to hypothesize about what potential barriers to learning might be and a willingness to erode and remove these barriers before even getting to the blueprint of a lesson plan (Meo, 2012). Access and inclusion have merged as concerns, and now stand united as a goal (Rose \& Gravel, 2010). Another revolutionary prise de conscience, in the midst of this demystifying process, is that many of the hands-on solutions which appear as congenial and immediately helpful, when analyzing barriers to access to learning, quickly show pedagogical potential for the inclusion of all learners, not just students with impairments, but also for students from non-traditional backgrounds, other cultures and languages, and so forth (Ralabate, 2011). The three principles of UDL, as well as the core guidelines of differentiated or interactive teaching, suddenly become not only tools that guarantee access to learning for students with cognitive and emotional impairment, but also significantly improve the learning experience of all our learners (Tegmark-Chita, Gravel, Serpa, Domings, \& Rose, 2012).

In the post-secondary sector the opposite transition is occurring. The discourse has focused on the legal imperative of access to learning for over two decades; institutions had created giant parallel systems to manage these needs, in the form of disability service providers; they had devised elaborate funding and support systems to allow the management of these issues and the provision of large-scale retrofitting (Houghton \& Fovet, 2012). At no point however-apart from very few exceptions-have colleges and universities, as a sector, tackled inclusion head on. The post-secondary sector perpetuates the illusion that access to learning can occur outside the class and that instructors do not and should not have responsibility over it. These institutions adhere-despite all the literature - to the belief that access to learning is solely a legal responsibility, not a reality that should be anchored in the pedagogical practices of the class. Up to now, the post-secondary sector has examined the needs expressed by students through the deficit model, refusing to accept that pedagogy needs to be revisited and adapted, and that student centeredness must translate into pragmatic and proactive curriculum redesign. At long last though, the realization is taking place here too: that access and inclusion are but two sides of the same coin and that the former cannot be achieved without the latter (King-Sears, 2009). 
The title of this paper highlights the need not just for awareness of the synchronicity between access and inclusion, but more importantly the urgency for the creation of a roadmap for the delicate process of navigating this synchronicity. What is meant by navigating a delicate conjuncture? Most educators are aware, implicitly or explicitly, of the paradigm shift described above. They see the growing need for the natural osmosis between these concepts to dribble down to the classroom, where it must trigger a rethink of our teaching practices and curriculum aspirations. However, navigating this conjuncture remains a very tenuous task for our society. The process that lies ahead is both crucial and delicate. Firstly, translating our concerns for access to learning and our focus on the social model of disability into our daily teaching practices represents a monumental reflective task (Novak, 2011). Educators need to be motivated and supported through this time- and resource-expensive process. Turning inclusion and access practices into a reality, available to all students, is a steady move towards more sustainable pedagogical practices, but it is also a heavy burden. It is important therefore for governments to realize what is at stake and support this change. Likewise, the merging of access and inclusion represents a complex process of change for schools and post-secondary institutions. The successful on-terrain fusion of both concepts will only continue to occur if we are willing to rethink 21st century pedagogy. The management of change process, which must accompany this rethink, is however not necessarily the forte of education as a field, whether this is examined globally or institutionally. Now that we have come to a global realization of the synchronicity between access and inclusion, our jurisdictions, governments, and school boards need to nurture, through effective and delicate management of change, the willingness of educators to navigate this paradigm shift. There is one substantial motivational force for these factors and conditions to align at this stage of history. Access, and therefore inclusion, is indeed no longer a minority discourse-it is very much a majority concern (Mole \& Fovet, 2013). 


\section{References}

Barnes, C. (2012). Understanding the social model of disability: Past, present and future. In: N. Watson, A. Roulestone and C. Thomas (Eds.) Routledge Handbook of Disability Studies. London: Routledge

Beach, M. (2010). Accommodations: Assisting students with disabilities. Tallahassee: Florida Department of Education.

Bradley, R., Danielson, L. E., \& Hallahan, D. P. (2002). Identification of learning disabilities: Research to practice. Mahwah, NJ: Erlbaum.

Gordon, D.T., Gravel, J.W., \& Schifter, L.A. (2009). A policy reader in universal design for learning (pp. 209-218). Cambridge, MA: Harvard Education Press.

Gradel, K., \& Edson, A. J. (2010). Putting universal design for learning on the higher ed agenda. Journal of Educational Technology Systems, Vol. 38(2), 111-121.

Houghton, M., \& Fovet, F. (2012) Reframing disability, reshaping the provision of services. Communiqué, Vol. 13 (1), 16-19

Katz, J. (2013). The three block model of universal Design for Learning (UDL): Engaging students in inclusive education. Canadian Journal of Education/Revue canadienne de l'éducation, Vol 36(1), 153-194

King-Sears, M. (2009). Universal design for learning: Technology and pedagogy. Learning Disabilities Quarterly, Vol. 32, 199-201

Kluth, P., Villa, R. A., \& Thousand, J. S. (2002). "Our school doesn't offer inclusion" and other legal blunders. Educational Leadership, Vol. 59 (4), 24-27.

Kosanovich, M. (2012). Using instructional routines to differentiate instruction: A guide for teachers. Portsmouth, NH: RMC Research Corporation, Center on Instruction.

Meo, G. (2012). Curriculum planning for all learners: Applying Universal design for Learning (UDL) to a high school reading comprehension program. Preventing School Failure: Alternative Education for Children and Youth, 52(2), pp. 21-30.
Mole, H., \& Fovet, F. (2013). UDL - From disabilities office to mainstream class: How the tools of a minority are addressing the aspirations of the student body at large. Collected Essays on Learning and Teaching, Vol. 6, 121-126.

Munn, P., \& Lloyd, G. (2005). Exclusion and excluded pupils, British Educational Research Journal, Vol. 31(2), 205-221.

Novak, G. M. (2011). Just-in-time teaching. New Directions for Teaching and Learning, Vol. 128, 63-73

Ralabate, P. K. (2011). Universal design for learning: Meeting the needs of all students. The ASHA Leader.

Rose, D.H., \& Gravel, J.W. (2010). Universal design for learning. In E. Baker, P. Peterson, \& B. McGaw (Eds.). International Encyclopedia of Education (3rd ed.). Oxford: Elsevier.

Schaufeli, W. B., \& Salanova, M. (2007). Efficacy or inefficacy, that's the question: burnout and work engagement, and their relationships with efficacy beliefs. Anxiety, Stress, \& Coping. An International Journal, Vol. 20, 177-196.

Tedesco, G. (2013). The Challenge of Inclusive Education in Relation to Differentiated Instruction. Masters Thesis, Ontario Institute for Studies in Education of the University of Toronto.

Tegmark-Chita, M., Gravel, J.W., Serpa, M. de L. B., Domings, Y., \& Rose, D.H. (2012). Using the universal design for learning framework to support culturally diverse learners. Journal of Education, Vol. 192(1), 17-22

Villa, R. A., \& Thousand, J. S. (2005). Creating an inclusive school (2nd ed.). Alexandria, VA: ASCD.

Visser, J., Daniels, H., \& Macnab, N. (2005) Missing. Children and young people with SEBD, Emotional and Behavioural Difficulties, Vol. 10(1), 43-54 


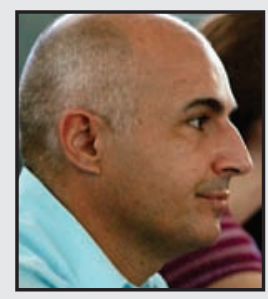

Frederic Fovet is the Director of the Office for Students With Disabilities at McGill University. A former lawyer dealing with issues of human rights, he is extremely focused on issues of disabilities and accessibility. He also holds a Masters of Education in Social, Emotional, and Behavioral Difficulties from Birmingham University in the United Kingdom and was a teacher in Special Education. Moreover, he was a principal of an experimental residential school for adolescents with learning disabilities and behavior difficulties for 12 years.

LINK TO:

http://www.mcgill.ca/osd/ 